\title{
Surveillance of transmitted HIV-1 antiretroviral drug resistance in the context of decentralized HIV care in Senegal and the Ebola outbreak in Guinea
}

\author{
Aristid Ekollo Mbange 1,2,3 0 , Djiba Kaba ${ }^{3,4,5}$, Abou Abdallah Malick Diouara ${ }^{1,6,7}$, Halimatou Diop-Ndiaye ${ }^{1,3}$, \\ Ndeye Fatou Ngom-Ngueye ${ }^{8}$, Ahmed Dieng ${ }^{9}$, Seynabou Lo ${ }^{9}$, Kine Ndiaye Toure ${ }^{8}$, Mamadou Fall ${ }^{3}$, \\ Wilfred Fon Mbacham², Mariama Sadjo Diallo ${ }^{4}$, Mohamed Cisse ${ }^{4}$, Souleymane Mboup ${ }^{1}$ \\ and Coumba Toure Kane $e^{1,3,10^{*}}$
}

\begin{abstract}
Objectives: Disruption in HIV care provision may enhance the development and spread of drug resistance due to inadequate antiretroviral therapy. This study thus determined the prevalence of HIV-1 transmitted drug resistance (TDR) in settings of decentralized therapy and care in Senegal and, the Ebola outbreak in Guinea. Antiretroviral-naive patients were enrolled following a modified WHO TDR Threshold Survey method, implemented in Senegal (JanuaryMarch 2015) and Guinea (August-September 2015). Plasma and dried blood spots specimens, respectively from Senegalese $(n=69)$ and Guinean $(n=50)$ patients, were collected for direct sequencing of HIV-1 pol genes. The Stanford Calibrated Population Resistance program v6.0 was used for Surveillance Drug Resistance Mutations (SDRMs).

Results: Genotyping was successful from 54/69 (78.2\%) and 31/50 (62.0\%) isolates. In Senegal, TDR prevalence was 0\% (mean duration since HIV diagnosis $4.08 \pm 3.53$ years). In Guinea, two patients exhibited SDRMs M184V (NRTI), T215F (TAM) and, G190A (NNRTI), respectively. TDR prevalence at this second site, however, could not be ascertained because of low sample size. Phylogenetic inference confirmed CRF02_AG predominance in Senegal (62.96\%) and Guinea (77.42\%). TDR prevalence in Senegal remains extremely low suggesting improved control measures. Continuous surveillance in both settings is mandatory and, should be done closest to diagnosis/transmission time and with larger sample size.
\end{abstract}

Keywords: Decentralization, Ebola, HIV-1 transmitted drug resistance, First-line regimen, Surveillance, West-Africa

\section{Introduction}

Genetic imprints of HIV-1 transmitted drug resistance (TDR) in therapy-naïve individuals may readily jeopardize the clinical benefits associated with antiretroviral therapy (ART). Currently this therapy is initiated in developing countries (DC) as a triple combination of two nucleosides reverse transcriptase inhibitors (NRTIs) and

\footnotetext{
*Correspondence: ctourekane@yahoo.co.uk; coumba.toure@iressef.org ${ }^{1}$ Institut de Recherche en Santé, de Surveillance Epidémiologique et de Formation (IRESSEF), Diamniadio, Sénégal

Full list of author information is available at the end of the article
}

a non-NRTI (NNRTI) [1]. These potent drugs primarily aim at suppressing viral load, by interfering with HIV-1 reverse transcriptase (RT) processivity [2]. TDR notably has the potential to increase the risk of virological failures (VF) [3], which detection is crucial to assess response to therapy.

Senegal and Guinea are two neighboring countries of West Africa which together with Central Africa (WCA) globally represents the second most affected region by HIV [4]. In 2016 an estimated 6.1 million people were living with HIV in WCA, although ART coverage remains one of the lowest (33\%). Moreover, the handful 
of patients on therapy are poorly retained on care, which may imply inadequate service delivery with possible consequences on the spread of drug resistance. Especially in fragile health systems like that of Guinea. This country has sustained the overwhelming effects of the Ebola outbreak between 2014 and 2015, with significant repercussions on the provision of HIV services [5]. Another major challenge in most WCA countries is the ineffective decentralization of HIV care. In Senegal, as of 2008, decentralized regions, other than the capital city Dakar, began witnessing upward trends in the proportion $(70 \%$ in 2013) of patients starting therapy [6]. These settings have been consistently reported with higher rates of VF (23.8-26.0\%) associated with acquired drug resistance (ADR) (15.9-17.7\%) between 2008 and 2011 [7, 8].

TDR published estimates in Guinea date back to 2009 (8.6\%) [9] and in Senegal to 2010 (1.04\% protease inhibitors, $4.16 \%$ NRTIs) [10]. This study determined and provided updates of TDR prevalence, with the overall goal of improving ART start and monitoring uptake in those challenged settings of HIV care. As such, the presumably long-term efficacy of first-line ART could be safeguarded.

\section{Main text \\ Methods \\ Patients' enrolment and settings}

The WHO threshold survey (TS) method [11] was slightly modified to enroll ART-naïve patients (women and men) irrespective of age (under or over 25 years) and, the number of pregnancies. In Guinea, enrolment was conducted between August and September 2015 at the ambulatory treatment center (ATC) of Donka national hospital (DNH), Conakry. This hospital hosts the largest HIV facility in Guinea and served as one of the Ebola virus treatment centers during the outbreak. In Senegal, patients were enrolled between January and March 2015 at the ATC of Dakar (University Teaching Hospital/UTH of Fann), which currently operates as the reference center for HIV management in Senegal. Recruitment also took place at the regional hospital of Saint-Louis (RHS); SaintLouis being one of the thirteen decentralized regions for HIV treatment and care in Senegal. Enrolment at respective sites was undertaken at the time of the CD4 threshold strategy of 500 cells $/ \mathrm{mm}^{3}$ for ART eligibility.

HIV guidelines in Senegal $[6,12,13]$ and Guinea [14, 15] are similar in many respects. Individuals willing to take an HIV test undergo a pre-/post-test counselling prior to medical and psychosocial support. Upon entering to care CD4 T-cells are enumerated and three-/ six-monthly thereafter (or when clinically indicated). First-line ART is started when CD $4<500$ cells $/ \mathrm{mm}^{3}$. At the RHS, a social assistant administers adherence counselling, which is mostly ensured by peers or support groups at respective ATCs that track care/treatment defaulters.

At the time of the study, recommended first-line therapies comprised two NRTIs (specifically Zidovudine/ Tenofovir + Lamuvidine/Emtricitabine) and one NNRTI (Nevirapine/Efavirenz). Confirmed cases of first-line failures (viral $\mathrm{RNA} \geq 1000$ copies/ml) are switched to second-line therapies with two NRTIs and one protease inhibitor. For prevention-for-mother-to-child-transmission, both countries adopted option $\mathrm{B}+$.

On-site viral load tests are available/operational since 2013 (ATC/Dakar), 2014 (ATC/DNH), 2016-2018 (RHS) and, provided six-monthly. For ATC/Dakar, these tests were previously offered at the reference Laboratory of Bacteriology-Virology (LBV) of the Aristide Le Dantec UTH in Dakar. Unlike Dakar, resistance testing is lacking in Guinea and decentralized settings of Senegal.

\section{Samples processing}

All patients in Senegal provided blood specimens $(5 \mathrm{ml})$, collected in EDTA-tubes and centrifuged to harvest plasma that was stored at $-80{ }^{\circ} \mathrm{C}$. In Guinea, blood was spotted (50 $\mu \mathrm{l} /$ spot) onto filter papers (Whatman ${ }^{\circledR}$; 903) before shipping to the LBV where all samples were genotyped. Dried blood spots (DBS) were also kept at $-80{ }^{\circ} \mathrm{C}$ until molecular analysis and, their preparation and shipping conditions have been described earlier [8].

\section{HIV-1 resistance genotyping}

Viral RNA was extracted from plasma and DBS using the QIAmp ${ }^{\circledR}$ Viral RNA Mini Kit (250) (Qiagen, Courtaboeuf France) and NucliSENS easyMag (bioMerieux, Craponne, France), respectively. cDNA Synthesis and PCR (nested-) were carried out in a one-tube reaction containing AMV-reverse transcriptase (Promega, USA). HIV-1 pol gene encoding the protease (PR) and partial RT drug-targets was sequenced following the ANRS protocol [16]. Using the Calibrated Population Resistance program v6.0 (http://cpr.stanford.edu), WHO Surveillance Drug Resistance Mutations (SDRMs) [17] were screened uniquely against the first-line antiretroviraltarget RT. Contigs were assembled on SeqMan ${ }^{\mathrm{TM}}$ II v5.08 (DNASTAR*, Lasergene Konstanz Germany). Consensus sequences were quality-controlled for possible contamination by computing pairwise genetic distances on MEGA v6.06.

\section{Phylogenetic and recombination analysis}

Multiple sequence alignment was executed with Mafft v7.31 [18] and, included reference sequences from HIV-1 subtypes A-K and several circulating recombinant forms (CRFs) [19]. Phylogenetic trees were inferred by the Maximum Likelihood method with PhyML v3.1 [20], under 
the GTR $+\Gamma_{5}+$ I nucleotide substitution model. The Subtree-Pruning-Regrafting heuristic search was applied for optimal tree topology. Branch statistic was computed by the Shimodaira-Hasegawa-approximate likelihood ratio test (SH-aLRT) [21]. Patterns of recombination, notably for outliers, divergent and, long-branch sequences, were determined through Boot-scanning using SimPlot v3.5.1. All trees were read and edited with MEGA.

\section{Statistical analysis}

Patients' data were summarized as frequencies, means $( \pm \mathrm{SD})$ and median (inter-quartiles, IQR) using Epi-info ${ }^{\text {TM }}$ v.7.2.1.

\section{Results}

\section{HIV-1 transmitted drug resistance in Senegal}

In total 69 ART-naïve patients were enrolled at the ATC/ Dakar (68.11\%) and RHS (31.88\%). The median age of the study population was 37 years (IQR 32-45) with females being mostly represented $(65.2 \%, 45 / 69)$ (Table 1$)$. At inclusion, mean time since HIV diagnosis (MTSD) was $4.08 \pm 3.53$ years. Fifty-four of $69(78.26 \%)$ isolates were successfully genotyped in their PR-RT $(53.62 \%, 37 / 69)$ and RT $(24.63 \%, 17 / 69)$ genomic regions. No SDRM was found leading to an estimated prevalence of $0 \%$ TDR. The CRF02_AG variant was the most widespread (62.96\%, $34 / 54)$ followed by, subtype C $(14.81 \%, 8 / 54), B$ and CRF06_CPX (5.55\% each, 3/54), A3 (3.70\%, 2/54) and, A1 $(1.85 \%, 1 / 54)$ (Figs. 1 and 2). The designated "Cx" cluster branched basal to the main $\mathrm{C}$ clade with strong support $(\mathrm{SH}$-aLRT $=98)$ suggesting a transmission network. Three unique recombinant forms (URFs) were identified (5.55\%): CRF02_AG/A3, CRF06_CPX/CRF02_AG, CRF06_CPX/A1/K (Fig. 1).

\section{HIV-1 transmitted drug resistance in Guinea}

At $\mathrm{DNH}$, included patients totaled 50 . The median age was 34 years (IQR 26-43) and females constituted more than half of the study population $(58.0 \%, 29 / 50)$ (Table 1$)$. Patients in their quasi-totality $(94.0 \%, 47 / 50)$ were diagnosed with HIV less than a year before sampling. All Guinean HIV-1 RT sequences were genotyped with a $62.0 \%(31 / 50)$ success rate. One isolate harbored the NNRTI-G190A SDRM, whereas another exhibited dualclass resistance carrying NRTI-M184V, T215F (thymidine-analogs mutation) and, NNRTI-K103N. CRF02_AG constituted $77.42 \%(24 / 31)$ of all HIV-1 infections followed by, CRF06_CPX $(6.45 \%, 2 / 31)$, subtype D and sub-subtype A3 (3.22\% each, 1/31) (Fig. 2). Equally three mosaics forms were characterized (9.67\%): A3/CRF02 AG and G/CRF02_AG forming a weak $(\mathrm{SH}$-aLRT $<85)$ monophyletic cluster and, A3/K (Fig. 2).
Table 1 Demographic and clinical characteristics of antiretroviral-naïve patients in Senegal and Guinea

\begin{tabular}{|c|c|c|}
\hline \multirow[t]{2}{*}{ Variables/Categories } & \multicolumn{2}{|c|}{$\begin{array}{l}\text { Frequency }(\%) / \text { Median } \\
\text { with interquartile [IQR] or Mean } \\
\text { with Standard Deviation (SD) }\end{array}$} \\
\hline & $\begin{array}{l}\text { Senegal } \\
\text { (Dakar + Saint- } \\
\text { Louis) } \\
\mathrm{N}=69\end{array}$ & $\begin{array}{l}\text { Guinea (Donka) } \\
\mathrm{N}=50\end{array}$ \\
\hline \multicolumn{3}{|l|}{ Gender } \\
\hline Female & $45(65.2)$ & $29(58.0)$ \\
\hline Male & $24(34.8)$ & $21(42.0)$ \\
\hline Age (years), median & $37.0[32.0-45.0]$ & $34.0[26.0-43.0]$ \\
\hline \multicolumn{3}{|l|}{ Age groups } \\
\hline$<25$ & $6(8.7)$ & $11(22.0)$ \\
\hline $25-39$ & $35(50.7)$ & $24(48.0)$ \\
\hline$\geq 40$ & $28(40.6)$ & $15(30.0)$ \\
\hline Mean years since HIV diagnosis & $4.08 \pm 3.53$ & $0.74 \pm 1.39$ \\
\hline \multicolumn{3}{|l|}{ Years since HIV diagnosis } \\
\hline$<1$ & $19(27.54)$ & $47(94.0)$ \\
\hline $1-3$ & $13(18.84)$ & - \\
\hline$>3$ & $34(49.28)$ & - \\
\hline Missing & $3(4.35)$ & $3(6.0)$ \\
\hline $\begin{array}{l}\mathrm{CD} 4\left(\mathrm{cell} / \mathrm{s} / \mathrm{mm}^{3}\right) \text {, Median } \\
\text { recent three months }\end{array}$ & $537.0[461.0-643.0]$ & $307.5[185.0-434.0]$ \\
\hline \multicolumn{3}{|l|}{ CD4 groups } \\
\hline$\leq 500$ & $22(31.88)$ & $31(62.0)$ \\
\hline$>500$ & $39(56.52)$ & $5(10.0)$ \\
\hline Missing & $8(11.59)$ & $14(28.0)$ \\
\hline $\begin{array}{l}\text { Viral load* }\left(\log _{10} \text { copies } / \mathrm{ml}\right) \text {, } \\
\text { median }\end{array}$ & - & $\begin{array}{l}5.52[4.84-6.31] \\
\text { (range 2.40-12.80) }\end{array}$ \\
\hline \multicolumn{3}{|l|}{ Viral load groups } \\
\hline$<3.30$ & - & $4(8.0)$ \\
\hline$\geq 3.30<4.0$ & - & $2(4.0)$ \\
\hline$\geq 4.0$ & - & $44(88.0)$ \\
\hline
\end{tabular}

*Quantitation of plasma viral RNA particles was done using the Generic HIV Viral Load Kit (Biocentric ${ }^{\circledR}$ )

\section{Discussion}

The $0 \%$ TDR prevalence found in Senegal comforts previous studies from this site that reported no NNRTIs mutations and, a decline in NRTIs TDR (4.16-0\%) between 1998 and 2006/2007 [10, 22]. This extremely low rate is contrary to that observed in a meta-analysis showing a $3.5 \%$ rate at 5-7 years after ART rollout in WCA [23] and, in Liberia (Monrovia) in 2013 (5.9\%) [24]. Such stable prevalence most likely reflects substantial inputs from AIDS control programs to minimize HIV risky behaviors. Furthermore, improvement in treatment compliance over the years and viral load control, at least at the ATC/ Dakar, may have contributed to this result.

Compared to the ATC/Dakar, viral load and resistance testing at the time of this investigation were 
hardly performed at the RHS. In a concurrent crosssectional study conducted in these two facilities, we showed significant odds of VF and ADR to first-line ART, taken for $\geq 12$ months, at the RHS (unpublished data). Despite the consistent rollout of antiretrovirals at decentralized sites since 2008, the $27.53 \%$ therapynaïve cases at the RHS harbored no SDRM. This observation underscores the importance of preventing new infections in a context of inadequate therapy monitoring. Nonetheless, the magnitude of TDR at the RHS remains to be ascertained because of the few isolates screened. The restrictive criteria of WHO-TS to apply in antenatal settings of low HIV prevalence may explain this limitation [25]. At Saint-Louis, this prevalence accounted for $0.3 \%$ among pregnant women [13].

The underrepresented proportion of patients $<25$ years old, especially in Senegal, might be perceived as an underestimation of TDR prevalence. This criterion and, primigravidity have shown limited sensitivities in identifying recent infections [25, 26]. The current study was implemented before the test-and-treat policy. In Malawi, an excellent study revealed higher misclassifications rates for antiretroviral start with the CD4 threshold of 500 cells $/ \mathrm{mm}^{3}$; namely between 350 and 650 cells $/ \mathrm{mm}^{3}$ with single measurements [27]. As such, the reliability of the CD4 count as a marker of recent infection (CD4 $>500$ cells $/ \mathrm{mm}^{3}$ ) may have implications for the WHO-TS in DC. Furthermore, this approach may defer treatment start, thereby increasing the likelihood of onward TDR [28]. Scrutinizing ART starters for pre-treatment drug resistance [29] therefore remains central for the optimization of first-line therapies in DC. The inconsistency in median CD4 $\left(537\right.$ cells $\left./ \mathrm{mm}^{3}\right)$ and MTSD $(4.08 \pm 3.53$ years $)$ in Senegalese patients may signify longer infections. This finding contradicts that seen in Guinean patients (median CD4, 307.5 cells/ $\mathrm{mm}^{3}$; MTSD, $0.74 \pm 1.39$ years). In Tanzania, older patients (38.9 \pm 10.1 years) presented a 19\% TDR prevalence (mean CD4, $478 \pm 223$ cells $/ \mathrm{mm}^{3}$, MTSD, $1.45 \pm 0.23$ years) [26]. Hence, sampling of SDRMs should be done closest to diagnosis/transmission time. Indeed, prolonged infections in the absence of drug pressure tend to recede to levels undetectable by Sanger sequencing [30].

The WHO-TS strategy requires a minimum of 34-47 samples to report TDR in DC. Regardless of this criterion and, in spite of the Ebola crisis it could be argued that TDR rate in Guinea has not known any increase from 2009 when the last survey was conducted [9]. The prevalence seems to have dropped from $8.6 \%$ to now $6.45 \%$, which is below that seen in Niger (8.3\%) [31]. Further studies are needed, however, to support this finding as TDR prevalence in Guinea could not be scored as low $(<5 \%)$, moderate $(5-15 \%)$ or, high $(>15 \%)$ [11]. Only few specimens could be genotyped, possibly because of low viral loads or sub-optimal storage conditions leading to viral genome breakages. Notably as DBS shipment to Senegal was delayed owing to fear of the Ebola virus.

SDRMs detected in Guinea may cause high-level resistance at initiation to Zidovudine (T215F), Lamivudine (M184V) and, Nevirapine/Efavirenz (G190A/K103N). These resistant genotypes have been previously described in therapy-naïve patients at DNH [9] and, with T215 revertants may persistently survive in drug-free environments unlike M184V and T215F [32, 33]. Ibe et al. [34] proposed such fitness property could be attributable to mutations (compensatory) occurring in other genomic regions.

Molecular phylogenetic confirmed CRF02_AG predominance in Western-Africa [35]. Recombination profiling warrants detailed near/full-length genome sequencing to assess the extent of HIV-1 diversity in our study settings [36].

\footnotetext{
(See figure on next page.)

Fig. 1 Phylogenetic inference of HIV-1 protease and partial reverse transcriptase sequences from antiretroviral-naïve patients in Senegal. Maximum likelihood analysis, implemented with the PhyML standalone package v3.1, involved 89 nucleotide sequences covering 1026 positions in the final dataset. Branch lengths are measured in the number of substitutions per site. The percentage of trees (SH-aLRT) in which the associated taxa clustered together is shown and values $\geq 85$ were significant. The " $C x^{\prime \prime}$ clade indicates a possible transmission network between two men (self-reported homosexual and heterosexual). Some clades were collapsed for clarity. Diamond triangles are study field isolates (right panel), of which those with three stars*** are unique recombinant forms (URFs). The left panel depicts boot-scanning plots for each URF queried against representative HIV-1 reference sequences obtained from the Los Alamos HIV database (https://www.hiv.lanl.gov). These sequences are color coded and included A3, CRF02_AG, F1, F2, B, D, CRF06_CPX, A1, K, C, H. Genomic splits or breakpoints were confirmed by reconstruction of phylogenetic trees focused on those unbroken regions (not shown). Boot-scanning was generated in SimPlot v3.5.1 under the Neighbor-Joining algorithm, modelled with the Kimura two-parameter and 100 bootstrap replicates (percentage of permuted trees on the $y$-axis). Boot-scanning was run with parameters of $50 \%$ consensus sequences, 300 base-pair window size, 10 base-pair step size (nucleotides position on the $x$-axis), and a nucleotide transition/transversion ratio of 2.0
} 


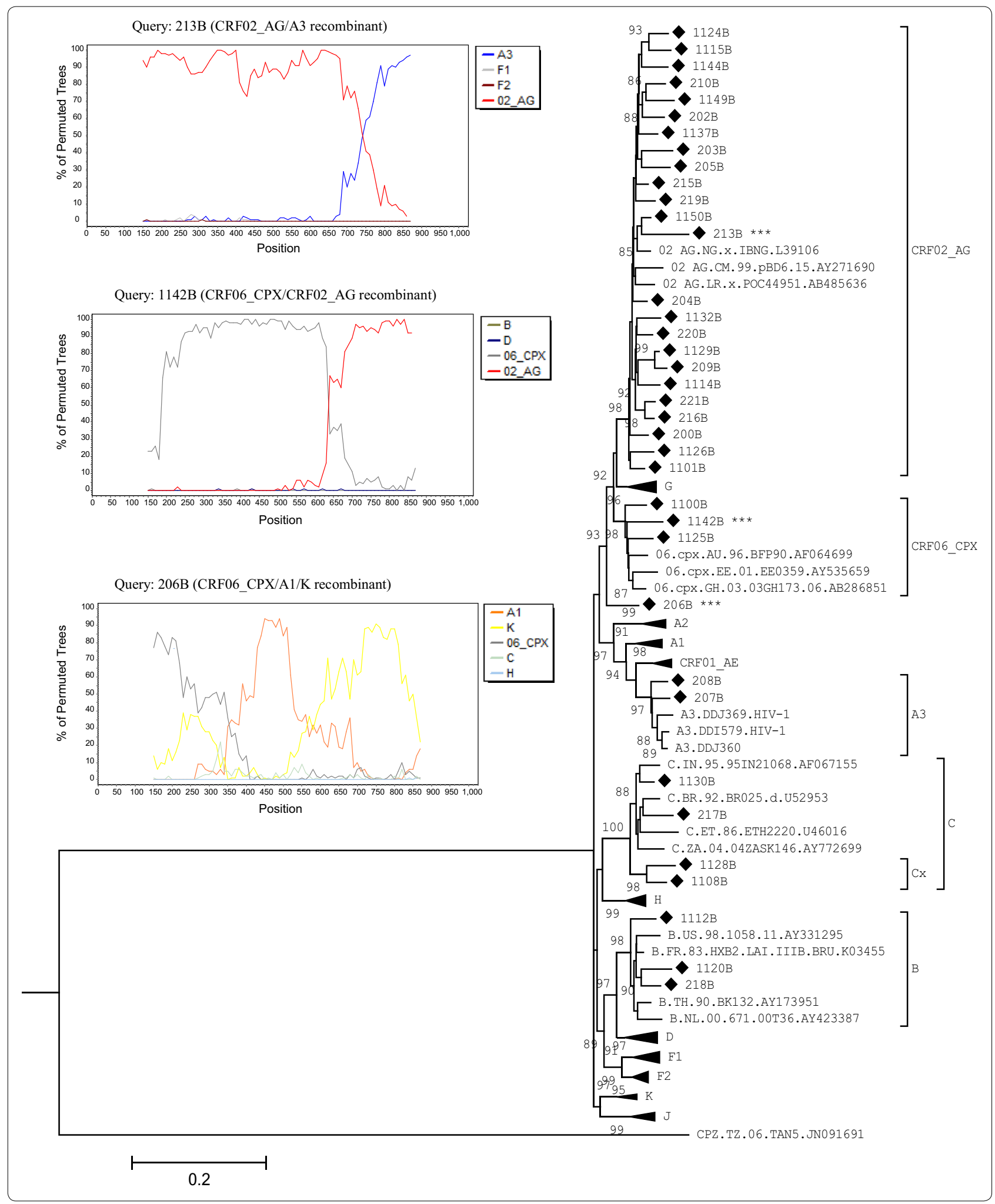




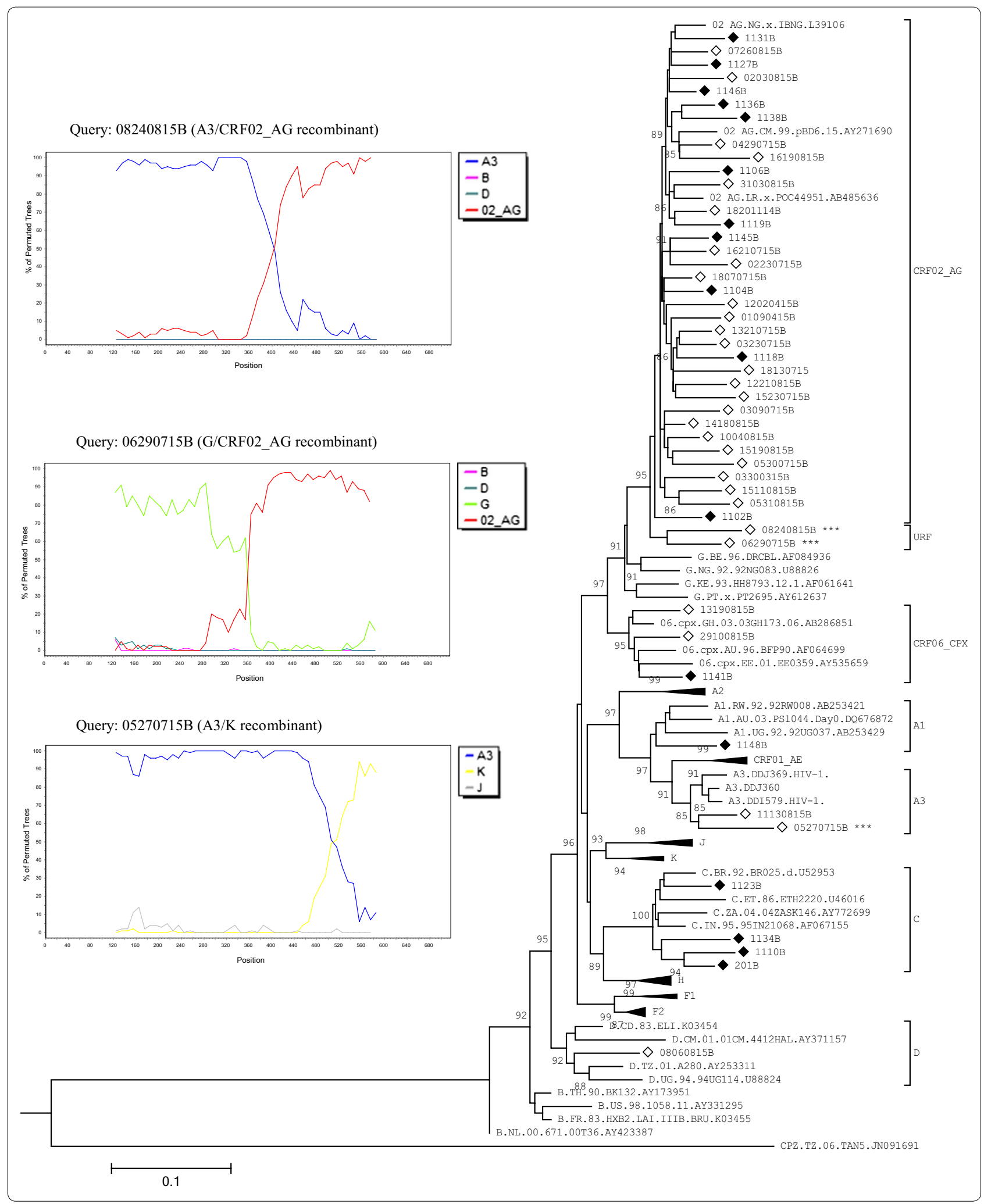




\section{(See figure on previous page.)}

Fig. 2 Phylogenetic inference of HIV-1 partial reverse transcriptase sequences from antiretroviral-naïve patients in Senegal and Guinea. Maximum likelihood analysis, implemented with the PhyML standalone package v3.1, involved 98 nucleotide sequences covering 717 positions in the final dataset. Branch lengths are measured in the number of substitutions per site. The percentage of trees (SH-aLRT) in which the associated taxa clustered together is shown and values $\geq 85$ were significant. Filled and empty diamond triangles are study field isolates, respectively from Senegal and Guinea. Some clades were collapsed for clarity. Unique recombinant forms (URFs) are indicated in the tree (right panel) with three stars***. The left panel shows Boot-scanning plots for each URF queried against representative HIV-1 reference sequences obtained from the Los Alamos HIV database (https://www.hiv.lanl.gov). These sequences are color coded and included A3, CRF02_AG, B, D, G, K, J. Genomic splits or breakpoints were confirmed by reconstruction of phylogenetic trees focused on those unbroken regions (not shown). Boot-scanning was run with the settings described in Fig. 1 (legends); at the difference that the window size was set at 250 base-pair

\section{Conclusion}

The prevalence of HIV-1 TDR in Senegal was extremely low but arguably moderate in Guinea, despite major challenges in the provision of HIV-related services. Further surveillance studies are needed especially in decentralized areas where treatment monitoring uptake is inadequate. Surveillance of TDR likewise should be enhanced in Guinea as disruption of health care due to the Ebola epidemic may have led to increased therapeutic failures.

\section{Limitations}

The sample size of this survey was not sufficiently informative of HIV-1 TDR dynamic at the decentralized and Ebola sites. Secondly, infections tended to be chronic in our sampling setting of Senegal, thus cautioning against extrapolation of the current $0 \%$ TDR. The use of conventional sequencing limits the detectability of resistant minority variants, which may have underestimated TDR prevalence.

\begin{abstract}
Abbreviations
ADR: acquired drug resistance; aLRT: approximate likelihood ratio test; ART: antiretroviral therapy; CD4: cluster of differentiation 4; CRF: circulating recombinant forms; DBS: dried blood spots; GTR: general time reversible; MAFFT: multiple alignment fast fourrier transformation; SDRM: surveillance drug resistance mutations; TDR: transmitted drug resistance; TS: threshold survey; URF: unique recombinant forms; VF: virological failure; WHO: world health organization.
\end{abstract}

\section{Authors' contributions}

CTK, SM, HDN, AAMD, NFNG and, MC contributed to the conceptualization and design of the study for all sites. SM and CTK sourced for funding. AD, SL, KNT, MSD, MF and, NFNG supervised, acquired and curated field data, performed confirmatory analysis for HIV-1/-2 sero-positivity and, enumeration of CD4 T-cells for patients with no records of CD4 counts in the recent 3 months. AAMD, MF, MSD and, DK, processed samples. MSD and DK performed viral load testing for therapy-naïve Guinean patients. AEM, DK and, AAMD performed resistance genotyping. AEM and AAMD performed phylogenetic inferences and Boot-scan analysis. CTK, HDN, AEM and, WFM validated and interpreted molecular data. AEM and DK wrote the original draft of the manuscript. AEM, CTK, SM, HDN, WFM and, MC critically revised the manuscript. All authors read and approved the final manuscript.

\section{Author details}

${ }^{1}$ Institut de Recherche en Santé, de Surveillance Epidémiologique et de Formation (IRESSEF), Diamniadio, Sénégal. ${ }^{2}$ The Biotechnology center, Department of Biochemistry, University of Yaoundé I, Yaoundé, Cameroon. ${ }^{3}$ Laboratoire de Bactériologie-Virologie, Centre Hospitalier Universitaire, Aristide Le
Dantec/Université Cheikh Anta Diop de Dakar, Dakar, Sénégal. ${ }^{4}$ Laboratoire de Biologie Moléculaire Nestor Bangoura/Hélène Labrousse, Hôpital National Donka, Conakry, Guinée. ${ }^{5}$ Service de Dermatologie-Vénéréologie Hôpital National Donka/UGAN, Conakry, Guinée. ${ }^{6}$ Département de Génie chimique et de Biologie Appliquée, Ecole Supérieure Polytechnique/Université Cheikh Anta Diop de Dakar, Dakar, Sénégal. ${ }^{7}$ Laboratoire de Bio-informatique, Université du Québec à Montréal, Montréal, Canada. ${ }^{8}$ Centre de Traitement Ambulatoire, Fann, Centre Hospitalier Universitaire, Dakar, Sénégal. ${ }^{9}$ Hôpital régional de Saint-Louis, Saint-Louis, Sénégal. ${ }^{10}$ Laboratoire de BactériologieVirologie CHNU Dalal Jam, Dakar, Sénégal.

\section{Acknowledgements}

We acknowledge all patients who consented and donated samples for the study. We are also gratefully indebted to all field staffs and local authorities.

\section{Competing interests}

The authors declare that they have no competing interests.

\section{Availability of data and materials}

The 54 Senegalese and 31 Guinean HIV-1 partial pol sequences produced in this study are available in the European Nucleotides Archives (ENA) through the following EMBL accession numbers: LT976712-LT976748 (http://www.ebi. ac.uk/ena/data/view/LT976712-LT976748), LT976780-LT976796 (http://www. ebi.ac.uk/ena/data/view/LT976780-LT976796), LT976749-LT976779 (http:// www.ebi.ac.uk/ena/data/view/LT976749-LT976779).

\section{Consent for publication}

Not applicable.

\section{Ethics approval and consent to participate}

This study was undertaken within the framework of West African Network of Excellence for TB, AIDS and Malaria (WANETAM). All countries involved in this project submitted study materials to their respective national ethics and administrative bodies for clearance. In Senegal, ethics and administrative clearance were obtained from the National Ethics Committee of Health Research and the Ministry of Public Health and Social Action, respectively. In Guinea, clearance was obtained from the National Ethics Committee for Health Research. All patients willingly accepted to participate and provided signed informed consent.

\section{Funding}

This study received support from the European and Developing Countries Clinical Trials Partnership (EDCTP) who made available funding through the WANETAM project (Grant No: 1049-WANETAM EDCTP-RegNet-2015).

The funding body has no role in the design of the study, collection, analysis, and interpretation of data and in writing the manuscript.

\section{Publisher's Note}

Springer Nature remains neutral with regard to jurisdictional claims in published maps and institutional affiliations.

Received: 6 July 2018 Accepted: 27 September 2018

Published online: 12 October 2018 


\section{References}

1. World Health Organization (WHO). Consolidated guidelines on the use of antiretroviral drugs for treating and preventing HIV infection 2013. http:// www.who.int/hiv/pub/guidelines/arv2013/download/en/index.html. Accessed 27 Nov 2016.

2. Hu WS, Hughes SH. HIV-1 reverse transcription. Cold Spring Harb Perspect Med. 2012:2:a006882

3. Wittkop L, Gunthard HF, de Wolf F, Dunn D, Cozzi-Lepri A, de Luca A, et al. Effect of transmitted drug resistance on virological and immunological response to initial combination antiretroviral therapy for HIV (EuroCoordCHAIN joint project): a European multicohort study. Lancet Infect Dis. 2011;11(5):363-71.

4. UNAIDS data 2017. http://www.unaids.org/sites/default/files/media asset/20170720_Data_book_2017_en.pdf. Accessed 25 Feb 2018.

5. Ribacke KJB, Saulnier DD, Eriksson A, Schreeb JV. Effects of the West Africa Ebola virus disease on health-care utilization-a systematic review. Front Public Health. 2016. https://doi.org/10.3389/fpubh.2016.00222.

6. CNLS Sénégal: Rapport annuel 2016. https://www.cnls-Senegal.org/ pdf/2017/Rapportcnls2016.pdf. Accessed 05 May 2017.

7. Diouara AAM, Diop-Ndiaye H, Kebe-Fall K, Tchiakpe E, Ndiaye O, Ayouba $A$, et al. Dried blood spots for HIV-1 drug resistance genotyping in decentralized settings in Senegal. J Med Virol. 2014;86:45-51.

8. Diouara AAM, Ndiaye HD, Guindo I, Bangoura N, Cisse M, Edmond T, et al. Antiretroviral treatment outcome in HIV-1-infected patients routinely followed up in capital cities and remote areas of Senegal, Mali and GuineaConakry. J Int AIDS Soc. 2014;17:19315

9. Charpentier C, Bellecave P, Cisse M, Mamadou S, Diakite M, Peytavin G, et al. High prevalence of antiretroviral drug resistance among HIV1-untreated patients in Guinea-Conakry and in Niger. Antivir Ther. 2011;16(3):429-33.

10. Diop-Ndiaye H, Toure-Kane C, Leye N, Ngom-Gueye NF, Montavon C, Peeters $\mathrm{M}$, et al. Antiretroviral drug resistance mutations in antiretroviral-naïve patients from Senegal. AIDS Res Hum Retroviruses. 2010;26(10):1133-8

11. Bennett DE, Myatt M, Bertagnolio S, Sutherland D, Gilks CF. Recommendations for surveillance of transmitted HIV drug resistance in countries scaling up antiretroviral treatment. Antivir Ther. 2008;13(Suppl 2):25-36.

12. Plan stratégique national de lutte contre le Sida 2014-2017. http://www. cnls-senegal.org/pdf/PSN\%202014-2017.pdf. Accessed 05 May 2017.

13. Rapport de situation sur la riposte nationale a l'épidémie de VIH/SIDA Sénégal: 2013-2014. http://www.unaids.org/sites/default/files/country/ documents/SEN_narrative report 2015.pdf. Accessed 05 May 2017.

14. CNLS Guinée, cadre stratégique national de lutte contre les ISTNIH/SIDA. http://www.invest.gov.gn/document/vih-plan-strategique-2013-2017. Accessed 17 Aug 2018.

15. CNLS Guinée Rapport National de la riposte VIH/SIDA 2014. http://www unaids.org/sites/default/files/country/documents/GIN_narrative_repor t_2015.pdf. Accessed 17 Aug 2018.

16. ANRS-France. http://www.hivfrenchresistance.org/ANRS-procedures.pdf. Accessed 03 Feb 2016.

17. Bennett DE, Camacho RJ, Otelea D, Kuritzkes DR, Fleury H, Kiuchi M, et al. Drug resistance mutations for surveillance of transmitted HIV-1 drug resistance: 2009 Update. PLoS ONE. 2009:4(3):e4724.

18. Katoh K, Standley D. Mafft multiple sequence alignment software version 7: improvements in performance and usability. Mol Biol Evol. 2013;30(4):772-80.

19. HIV Circulating Recombinant Forms (CRFs). https://www.hiv.lanl.gov/ content/sequence/HIV/CRFs/CRFs.html. Accessed 17 Dec 2017.

20. Guindon S, Dufayard JF, Lefort V, Anisimova M, Hordijk W, Gascuel O. New algorithms and methods to estimate maximum-likelihood phylogenies: assessing the performance of PhyML 3.0. Syst Biol. 2010;59(3):307-21.
21. Anisimova M, Gil M, Dufayard JF, Dessimoz C, Gascuel O. Survey of branch support methods demonstrates accuracy, power, and robustness of fast likelihood-based approximation schemes. Syst Biol. 2011;60(5):685-99.

22. Ayouba A, Lien TTX, Nouhin J, Vergne L, Aghokeng AF, Ngo-GiangHuong $\mathrm{N}$, et al. Low prevalence of HIV type 1 drug resistance mutations in untreated, recently infected patients from Burkina Faso, Cote d'Ivoire, Senegal, Thailand, and Vietnam: The ANRS 12134 study. AIDS Res Hum Retroviruses. 2009;25(11):1193-6.

23. Gupta RK, Jordan MR, Sultan BJ, Hill A, Davis DHJ, Gregson J, et al. Global trends in antiretroviral resistance in treatment-naïve individuals with HIV after rollout of antiretroviral treatment in resource-limited settings: a global collaborative study and meta-regression analysis. Lancet. 2012:380:1250-8.

24. Loubet P, Charpentier C, Visseaux B, Nuta C, Adu E, Chapplain JM, et al Short communication: Prevalence of HIV-1 transmitetd drug resistance in Liberia. AIDS Res Hum Retroviruses. 2014;30(9):863-6.

25. Bussmann H, Gomez FH, Roels TH, Wester CW, Bodika SM, Moyo S, et al. Prevalence of transmitted HIV drug resistance in Botswana: lessons learned from the HIVDR-threshold survey conducted among women presenting for routine antenatal care as part of the 2007 national sentinel survey. AIDS Res Hum Retroviruses. 2011;27(4):365-72.

26. Kasang C, Kalluvya S, Majinge C, Stich A, Bodem J, Kongola G, et al. HIV drug resistance (HIVDR) in antiretroviral therapy-naïve patients in Tanzania not eligible for WHO threshold HIVDR survey is dramatically high. PLOS ONE. 2011;6(8):e23091.

27. Schooley AL, Kamudumuli PS, Vangal S, Tseng CH, Soko C, Parent J, et al. CD4 variability in Malawi: Implications for use of a CD4 threshold of 500 cells $/ \mathrm{mm}^{3}$ versus universal eligibility for antiretroviral therapy. Open Forum Infect Dis. 2016. https://doi.org/10.1093/ofid/ofw180.

28. Paraskevis D, Kostaki E, Magiorkinis G, Gargalianos P, Xylomenos G, et al. Prevalence of drug resistance among HIV-1 treatment-naive patients in Greece during 2003-2015: transmitted drug resistance is due to onward transmissions. Infect Genet Evol. 2017:54:183-91.

29. World Health Organization (WHO). Surveillance of HIV drug resistance in adults initiating antiretroviral therapy pre-treatment HIV drug resistance): concept note. http://www.who.int/hiv/pub/drugresistance/pretreatme nt_drugresistance/en/. Accessed 27 May 2017.

30. Gianella S, Richman DD. Minority variants of drug-resistant HIV. J Infect Dis. 2010;202(5):657-66

31. Mamadou S, Hanki Y, Maazou ARA, Aoula B, Diallo S. Genetic diversity and drug resistance mutations in HIV-1 from untreated patients in Niamey, Niger. ISRN Microbiol. 2011. https://doi.org/10.5402/2011/797463.

32. Castro H, Pillay D, Cane P, Asboe D, Cambiano V, Phillips A, et al. Persistence of HIV-1 transmitted drug resistance mutations. J Infect Dis. 2013;208:1459-1463

33. Wainberg MA, Moisi D, Oliveira M, Toni TD, Brenner BG. Transmission dynamics of the M184V drug resistance mutation in primary HIV infection. J Antimicrob Chemother 2011;66:2346-9

34. Ibe S, Shigemi U, Sawaki K, Fujisaki S, Hattori J, Yokomaku Y, et al. Analysis of Near Full-Length Genomic sequences of drug-resistant HIV-1 spreading among therapy-naïve individuals in Nagoya, Japan: amino acid mutations associated with viral replication activity. AIDS Res Hum Retroviruses 2008:24(8):1121-5

35. Lihana R, Ssemwanga D, Abimiku A, Ndembi N. Update on HIV-1 diversity in Africa: decade in review. AIDS Rev 2012;14:83-100.

36. Novitsky V, Moyo S, Lei Q, DeGruttola V, Essex M. Importance of viral sequence length and number of variable and informative sites in analysis of HIV clustering. AIDS Res Hum Retroviruses. 2015;31(5):531-42. 